\title{
Innovación a través del arte en la Escuela
}

\author{
María del Rocío Ripoll Lluquet
}

Valencia, España, UPV, mrocioripoll@gmail.com

\section{Resumen}

El arte en la educación es muy importante. Muchas veces, y a pesar de estar siempre presente en las aulas, pasa a formar parte de alguna asignatura secundaria, en ocasiones, pasando desapercibido, y solo se recurre a él cuando se le necesita; ya sea para un proyecto, un regalo... Nosotros, como docentes, rara vez nos damos cuenta de lo esencial que puede llegar a ser, pues permite a su vez adquirir competencias que son imprescindibles para el desarrollo de los alumnos.

Las escuelas de hoy en día se esfuerzan por llevar un aprendizaje basado en proyectos, en la que se les pide a los alumnos la capacidad de trasladar sus conocimientos al mundo real; y este aprendizaje basado en proyectos, lleva implícito el arte, la necesidad de crear. Y hablando de proyectos y de la importancia de dar rienda suelta a la imaginación, ¿Es posible recurrir al arte como elemento esencial para trabajar este tipo de educación? ¿Podría la animación ser capaz de transmitir los conocimientos adquiridos y trabajar de la mano de la creatividad?

Pues bien, en este proyecto, se hace uso de la animación, en concreto, de la técnica del Stop motion, para que los alumnos puedan traspasar sus conocimientos adquiridos en las distintas materias, sin dejar de lado su creatividad. Pues con ella, se puede llevar a cabo este tipo de proyectos que relacionan las distintas áreas y de los que tan centrados están las escuelas de hoy en día. Por su atractivo y fácil uso en el aula, se convierte en una herramienta idónea para trabajarla en clase. Dando lugar a proyectos más cercanos y creativos capaces de plasmar el aprendizaje adquirido y sin dejar de lado a la creatividad, que tan importante es.

Como educadores, es nuestro deber tener siempre presente el arte en nuestras clases, pues es tan importante saber desarrollar los conocimientos adquiridos y plasmarlos en el mundo real, como desarrollarlos a través de proyectos que den rienda suelta a esa creatividad.

Palabras clave: Arte, educación, creatividad, animación, Stop motion, imaginación, proyectos. 


\section{Introducción}

Nos encontramos en una sociedad llena de cambios, donde el lugar que en antaño ocupaban las palabras, ahora es la imagen la que va ganando el terreno. A pesar de que con la revolución tecnológica, esto haya incrementado, lo cierto es que desde bien conocida la imagen, ésta siempre ha sido capaz de expresar lo que con palabras a veces nos es difícil de explicar.

Por ello, en este proyecto se hace hincapié en la imagen, en el arte, en la creatividad. Porque a pesar de que esté muy poco valorada en los centros educativos, no se le suele dar la importancia que debería. Hoy en día, nos centramos en llevar a cabo una educación basada en proyectos y en muchas ocasiones lo docentes se enfrentan al reto de como conseguir llevar a cabo este tipo de aprendizaje, de enseñanza. Pues bien, ahí debería entrar la imagen, para poder expresar a través de ella nociones aprendidas en distintas materias.

A través de la imagen, los alumnos son capaces de transmitir cosas, son capaces de proyectar lo aprendido sin la necesidad de hacer un recital. Son capaces de llevar a cabo esa metodología basada en proyectos, en la que la imagen debería estar siempre presente. Usar un medio audiovisual como puede ser la animación, es una herramienta muy útil que muchos centros educativos ya han puesto en práctica hoy en día, pues es usada en muchas ocasiones para enseñar nuevos conceptos. Continuamente acudimos a videos para aclarar a nuestros alumnos un concepto que no ha quedado claro, o simplemente para enseñarles una idea. Por ello, nuestros alumnos, no solo deberían saber captar la información de estos medios, sino que se hace esencial que sepan hacer uso de ellos y ser capaces de transmitir sus propios conocimientos a través de medios audiovisuales.

Ahora bien, se nos hace casi imposible entender como niños de 7 años pueden ser capaces de hacer un buen uso de esta técnica y saber transmitir los conocimientos aprendidos en las diferentes materias a través de ella. Bien, precisamente por eso hacemos uso de la animación. Concretamente, de la técnica del Stop motion, que no solo destaca por su fácil acceso al aula, al ser económica y no necesitar de muchos medios, sino que además es capaz de captar la atención de cualquier público espectador, y eso, en una edad tan temprana en la que cada niño es único, se le debe enseñar a desarrollar esa parte creativa que tan importante es. Otra ventaja que se puede decir es que nuestros alumnos, podrían aprender jugando. Y a través del juego, se expresan, comparten, aprenden, sociabilizan e intercambian roles; y esto último es muy importante a tener en cuenta en el aprendizaje basado en proyectos, y por eso hoy en día está cobrando importancia. Este cambio o asignación de roles consiste en asignar a cada niño un rol que tendrá que representar hasta nueva orden o cambio de rol. Así, los niños tímidos, por ejemplo, deben ser capaces de hacer de portavoces, y así, sucesivamente. 
La técnica del stop motion es ideal para trabajar con nuestros alumnos, tengan la edad que tengan. No ayuda solo a desarrollar la creatividad de nuestros pequeños, sino a captar la atención incluso de aquellos alumnos que puedan no sentirse identificados con la metodología empleada en clase.

\section{Objetivos}

Dado que hacemos referencia a unidades basadas en proyectos, y nos centramos en una forma distinta de enseñar, prestando atención al desarrollo de la creatividad y teniendo en cuenta que partimos de la base de una educación individualizada, donde cada alumno es diferente, único y especial, y por tanto, el profesor ha de ser flexible a la hora de enseñar en clase diferentes conceptos, y ha de ser capaz de explicarlos de distintas formas, los objetivos serán los siguientes:

- A través de un lenguaje visual se pretende desarrollar la creatividad.

- Haciendo uso de proyectos globales y multidisciplinares, hacer buen uso de los conocimientos y saber integrarlos adecuadamente.

- Usar el arte como medio de expresión para representar una idea o fijar conocimientos.

- Hacer un buen uso del lenguaje audiovisual, así como comprender su complejidad $\mathrm{y}$ beneficios.

- Mejorar la búsqueda de información a través del Aprendizaje Basado en Proyectos.

- Mejorar las habilidades sociales al trabajar en equipo.

\section{Metodología empleada}

Si témenos en cuenta que pudimos poner en práctica este tipo de proyecto en una clase donde las edades de los niños circulan alrededor de 6 años, es importante en primer lugar haber seguido a lo largo del curso una dinámica que favorezca esa enseñanza-aprendizaje basado en proyectos. Posteriormente, se ha de buscar la unidad y asignatura o asignaturas con las que usaremos este tipo de metodología y proyecto y se les explicará a los alumnos en que consiste la técnica del Stop Motion. Esta técnica suele agradarles mucho y les 
motiva a empezar bien el proyecto, pues ¿Quién no ha soñado alguna vez poder dar vida a un objeto? Pues algo similar ocurre con esta técnica de animación, en la que los alumnos han de crear su propia historia haciendo uso de todo tipo de materiales, ya sean, lápices, goma eva, pizarra, números, dibujos, pinturas, palabras...

Así pues, una de las metodologías a utilizar en este proyecto está basada y centrada más en el aprendizaje basado en proyectos, en el cual nuestros alumnos aprenden mediante estos proyectos a enlazar contenidos y dar respuesta a problemas en el día a día.

Como al fin y al cabo son niños, es conveniente dejarles claro el tema a tratar. Pues no es lo mismo hablar de sentimientos, que de plantas. Es importante que el tema sea atractivo, con el fin de motivarles y sacar lo mejor de ellos.

Para este tipo de actividad, sería conveniente crear grupos, y hablando de grupos, ¿qué mejor que adjudicar roles a cada miembro? Esto es importante que si no hemos usado esta dinámica de los roles en clase hasta ahora, seamos capaces de explicárselo bien y hacer que realmente se sientan conectados con su rol a representar. En esta actividad, los roles serían, coordinador, fotógrafo, motivador, representante o portavoz, diseñador y escenógrafo, por ejemplo.

Llega el momento de explicarles el tema a tratar, y esto es importante que no dure mucho tiempo, pues se presupone que lo habrán dado simultáneamente en otra de las asignaturas y lo tienen bien aprendido. En este caso, el tema a tratar fue el de las plantas, muy sencillito, pero lo suficiente para captar su atención.

Pero como es importante saber llegar a nuestros alumnos, y esto se consigue siendo flexible, ésta no ha sido la única metodología a utilizar. Entre otras, destacamos la metodología de investigación, al haber tenido conocimiento previo del tema a raíz de estudiarlo anteriormente e investigar un poco sobre ello. Por su parte, el profesor también se anticipó a aquellas preguntas que pudieran demandar en un futuro sus alumnos, y a esto se le llamaría metodología proactiva. Y por último, no hay que olvidarnos del trabajo cooperativo, que tan importante es hoy en día para el desarrollo personal, cognitivo y social de nuestros alumnos.

Así pues, se lleva a cabo el audiovisual, en el que al contar con poca edad, el profesor supervisa y ayuda, así como lleva a cabo el posterior montaje de los fotogramas.

\section{Resultados}

Cuando le ponemos empeño a la educación y nos involucramos al máximo, nos damos cuenta de lo importante que es enseñar de diversas formas, y no aferrarse a una sola. Es 
sorprendente como incluso con niños tan pequeños, se puede apreciar ese empujón de motivación que les crea este tipo de actividades, de aprendizaje. En cuestión de segundos, conseguimos captar su atención y colaboramos a ese aprendizaje en el que jugando, adquieren conocimientos y habilidades.

Mis alumnos se aferraron bien a su posición de roles y llevaron su papel más allá de su imaginación. Es una buena forma de comenzar motivándoles para una actividad grupal, cooperativa.

Como en este caso tratamos el tema de las plantas, dejaré aquí abajo algún que otro fotograma en el que se aprecie su evolución y desarrollo. En este ejercicio concreto, usamos, acrílico, goma-eva, y lápices de colores. Pero cualquier material habría servido. Es importante tener en cuenta que en eso consiste la creatividad, el arte, en dejarles ser libres, pues hay mil maneras de llegar a una misma conclusión. La imagen, como vemos, cobra vida.

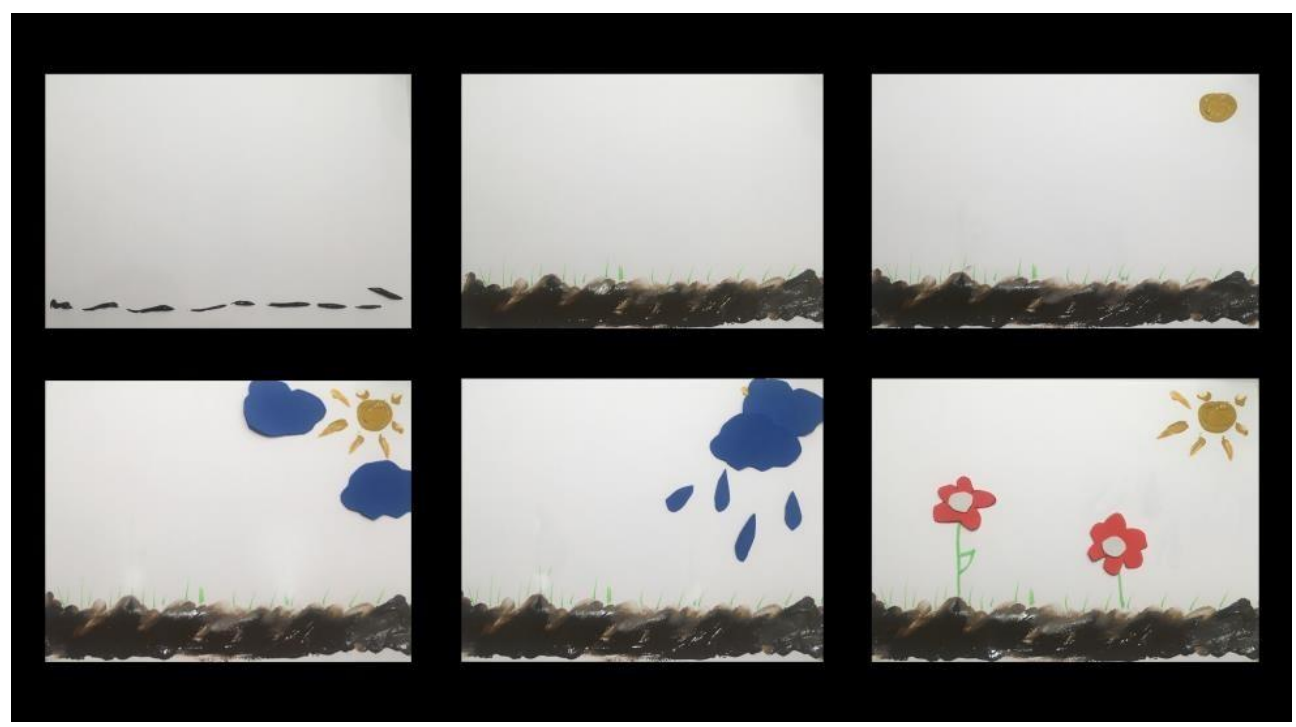

Fig. 1 Stop motion, la vida de una planta

Font: Edwards, $B$ (2005)

\section{Conclusiones}

Como profesores, hemos de ser conscientes del cambio que se está produciendo en nuestra sociedad, y por ello, hemos de ser conscientes de que no existe una única y clásica vía de enseñar a nuestros alumnos. Hemos de esforzarnos por una educación más individualizada, 
y ser capaces de aceptar esa flexibilidad, para que en momentos que necesitemos, podamos hacer uso de ella y seamos capaces de llegar a los alumnos que por alguna razón, están desmotivados en el aula.

Actividades y proyectos como este suelen captar la atención de casi todos nuestros alumnos y son verdaderamente útiles para enseñarles distintas vías de adquirir conocimientos y habilidades, así como de aprender a trabajar en equipo.

Seamos flexibles, seamos creativos y aprendamos jugando.

\section{Referencias}

Arnheim. R. (1997). Arte y percepción visual. Madrid: Alianza.

Aymerich, C y M. (1976). Expresión y Arte en la Escuela 2: La expresión plástica. Barcelona: Teide. Coll Espinosa. F. J. (2006). Dinámicas entre creación y procesos terapeúticos. Murcia: Universida de Murcia.

Cartier Bresson. H. (2003). Fotografiar del natural. Barcelona: Gustavo Gili.

Diekstra. R. (2016). “Aprendizaje social y emocional, habilidades para la vida”. 8/10/2018, de nueces y neuronas. Recuperado de: http://www.nuecesyneuronas.com/habilidaes-la-vida-renediekstra/

Durán. G., Sánchez. J. (1954). La psicología de los artistas. Madrid: Espasa-Calpe.

Eisner, E. W. (2004). El arte y la creación de la mente: el papel de las artes visuales en la transformación de la conciencia. Paidós.

Newhall, B. (2002). Historia de la fotografía. Barcelona: Gustavo Gili.

Ripoll. M.R. (2016) Adolescencia y Melancolía. Proyecto educativo con técnica de Stop motion.

Madrid: UAM.

Robert. J., Stenberg and Todd., Lubart. J. (1995). La creatividad en una cultura conformista: Un desafío a las masas. Barcelona: gráfiques 92, S.A.

Robinson. K. (2011). Out of minds: Learning to be creative. United Kingdom:Capstone publishing.

Ruíz. (2014) La animación como herramienta didáctica. [tesina de máster] Madrid: Universidad Autónoma de Madrid.

Saénz Valiente. R. (2006). Arte y técnica de animación. España: Ediciones de la flor.

Selby, A. (2009). Animación: Nuevos proyectos y procesos creativos. Barcelona: Parramón ediciones.

Taylor. R. (2000). Enciclopedia de la animación: una guía completa de técnicas paso a paso acompañada de una notable muestra de obras terminadas. Barcelona: editorial Acanto. 